Article

\title{
Strain Rate Effect on Tensile Behavior for a High Specific Strength Steel: From Quasi-Static to Intermediate Strain Rates
}

\author{
Wei Wang ${ }^{1,2}$, Yan Ma ${ }^{1,2}$ (D), Muxin Yang ${ }^{1}$, Ping Jiang ${ }^{1}$, Fuping Yuan ${ }^{1,2, *}$ and Xiaolei Wu ${ }^{1,2}$ \\ 1 State Key Laboratory of Nonlinear Mechanics, Institute of Mechanics, Chinese Academy of Sciences, No. 15, \\ North 4th Ring, West Road, Beijing 100190, China; wangwei1@imech.ac.cn (W.W.); \\ mayan@imech.ac.cn (Y.M.); woshiamu@126.com (M.Y.); jping@imech.ac.cn (P.J.); xlwu@imech.ac.cn (X.W.) \\ 2 School of Engineering Science, University of Chinese Academy of Sciences, Beijing 100190, China \\ * Correspondence: fpyuan@Inm.imech.ac.cn; Tel.: +86-10-82544409; Fax: +86-10-82543977
}

Received: 6 December 2017; Accepted: 27 December 2017; Published: 29 December 2017

\begin{abstract}
The strain rate effect on the tensile behaviors of a high specific strength steel (HSSS) with dual-phase microstructure has been investigated. The yield strength, the ultimate strength and the tensile toughness were all observed to increase with increasing strain rates at the range of 0.0006 to $56 / \mathrm{s}$, rendering this HSSS as an excellent candidate for an energy absorber in the automobile industry, since vehicle crushing often happens at intermediate strain rates. Back stress hardening has been found to play an important role for this HSSS due to load transfer and strain partitioning between two phases, and a higher strain rate could cause even higher strain partitioning in the softer austenite grains, delaying the deformation instability. Deformation twins are observed in the austenite grains at all strain rates to facilitate the uniform tensile deformation. The B2 phase (FeAl intermetallic compound) is less deformable at higher strain rates, resulting in easier brittle fracture in B2 particles, smaller dimple size and a higher density of phase interfaces in final fracture surfaces. Thus, more energy need be consumed during the final fracture for the experiments conducted at higher strain rates, resulting in better tensile toughness.
\end{abstract}

Keywords: high specific strength steel; strain rate effect; intermediate strain rates; strain partitioning; deformation twins

\section{Introduction}

Metals and alloys with high strength and ductility are always desirable in applications for automobiles, aerospace and military defense. In recent decades, several design strategies have been proposed to reach such expectations, such as transformation-induced plasticity (TRIP) [1-3], twinning-induced plasticity (TWIP) steels [2-5], and dual-phase (DP) steels [6,7]. Recently, high specific strength steels (HSSS) with low density, achieved by adding $\mathrm{Al}$ (3-12 wt. \%), have been widely studied due to their excellent mechanical properties, such as high specific yield strengths and large uniform elongations [8-19]. Most of these HSSS are based on Fe-Al-Mn-C alloy system (so called TRIPLEX steels), and consist of fcc austenite matrix, bcc ferrite matrix and finely dispersed $\kappa$-carbides $\left((\mathrm{Fe}, \mathrm{Mn})_{3} \mathrm{AlC}\right.$. type $)$ with nanometer size.

More recently, a HSSS with chemical composition of Fe-16Mn-10Al-0.86C-5Ni (wt. \%) has been developed [20]. This HSSS with a dual-phase microstructure and ultrafine grains was found to show excellent mechanical properties, such as high specific strength and large elongation (a combination of a specific yield strength of $200 \mathrm{MPa} \cdot \mathrm{g}^{-1} \cdot \mathrm{cm}^{3}$ and uniform elongation of $16 \%$, which can hardly be achieved in other high-strength steels). Kim et al. [20] has attributed the outstanding mechanical properties of this HSSS to the precipitation strengthening by the brittle B2 intermetallic compound. 
In our previous work [21,22], the stress/strain partitioning between the constituent phases and the back-stress-induced strain hardening have been found to play an important role during the plastic deformation for this HSSS, since the B2 phase was found to be deformable.

The HSSS can be considered as a perfect candidate for the advanced impact-tolerant structures in the automobile industry due to its excellent mechanical properties. It is widely accepted that the plastic flow behaviors and the corresponding deformation mechanisms are highly dependent on the loading rate for metals and alloys [23-40]. It is also well known that the observed resistance to plastic deformation is a rate-controlling process and can be affected by the strain rate $[23-25,27,28]$. The quasi-static tensile behaviors and the dynamic behaviors at high strain rates $\left(\sim 10^{3} / \mathrm{s}\right)$ for TRIP steels, TWIP steels, DP steels and HSSS have been well characterized in previous research $[1,2,20,41-50]$, while there is very limited experimental data on various steels at the intermediate strain rates (from 1 to 100/s) [51-55], which is an extremely important transition region in application of automobile industry, since vehicle crushing often happens in this strain rate range or within an even higher strain rate range. Thus, the potential applications for the HSSS in the automobile industry require a comprehensive understanding of deformation physics subjected to dynamic loading at intermediate strain rates.

In the HSSS with dual-phase microstructure, the strain rate sensitivity (SRS) is quite different for the soft fcc $\gamma$-austenite and the hard B2 phase. Thus, the loading rate can affect the stress/strain partitioning between these two phases and the resultant flow behaviors for this HSSS. Moreover, the strain rate effect on the deformation mechanisms for both phases in the HSSS is still unknown. For this perspective, a series of uniaxial tensile tests over a wide range of strain rates $(0.0006-56 / \mathrm{s})$ have been conducted on this HSSS. The strain rate effect on the flow behaviors was studied, and the rate-related constitutive equation was obtained for this HSSS. Moreover, the corresponding deformation mechanisms were revealed by the subsequent microstructure observations.

\section{Materials and Methods}

The HSSS (Fe-16.4Mn-9.9Al-0.86C-4.8Ni-0.008P-0.004S, wt. \%) was produced using arc melting under protection of pure argon atmosphere, and the detailed procedures for preparing the hot-rolled (HR) strips can be found in our previous papers [21,22]. The HR strips with a thickness of $3.9 \mathrm{~mm}$ were annealed at $1000{ }^{\circ} \mathrm{C}$ for $1 \mathrm{~h}$ first, and then were cold rolled (CR) into a final thickness of $1.3 \mathrm{~mm}$ with a thickness reduction of $66 \%$. The CR sheets were then annealed at $900{ }^{\circ} \mathrm{C}$ for $15 \mathrm{~min}$, followed immediately by water quenching. Before and after tensile tests, the microstructures of the HSSS were characterized by electron back-scattered diffraction (EBSD) and transmission electron microscopy (TEM). For EBSD acquisition, a scanning area of $60 \times 40 \mu \mathrm{m}^{2}$ was chosen and a scanning step of $0.1 \mu \mathrm{m}$ was used. The tensile fracture surfaces were also characterized by scanning electron microscopy (SEM). The detailed description of the sample preparation and the operating procedures for obtaining EBSD and TEM images can also be found in our previous papers [21,22].

Tensile tests at five different strain rates $(0.0006,0.05,1.2,3.6,56 / \mathrm{s})$ were conducted in the present study. Three experiments were conducted for each strain rate to check the repeatability. The quasi-static uniaxial tensile tests (strain rates of $0.0006,0.05 / \mathrm{s}$ ) were conducted using an MTS Landmark testing machine, and the dog-bone-shaped tensile specimens with a gauge length of $20 \mathrm{~mm}$, a width of $4 \mathrm{~mm}$ and a thickness of $1.3 \mathrm{~mm}$ (with loading direction parallel to the rolling direction) were used (as shown in Figure 1a). A $10 \mathrm{~mm}$ gauge extensometer was used in the quasi-static uniaxial tensile tests to measure the strain. The tests at intermediate strain rates were conducted using a servo-hydraulic high speed tensile testing machine (HTM5020, Zwick, Ulm, Germany). This high speed tensile testing machine has experimental capabilities for a maximum crosshead displacement of $350 \mathrm{~mm}$, a maximum load of $50 \mathrm{kN}$ and a maximum velocity of $20 \mathrm{~m} / \mathrm{s}$. The data synchronous acquisition is $1 \mathrm{MHz}$ for the high speed tensile testing machine. The specimens for the tests at intermediate strain rates have a gauge length of $10 \mathrm{~mm}$, a width of $5 \mathrm{~mm}$ and a thickness of $1.3 \mathrm{~mm}$ (with loading direction parallel to the rolling direction), and the schematic illustration for the specimens tested at intermediate strain rates is shown in Figure 1b. A piezo-electric type load cell was used to measure the load during the 
tests at intermediate strain rates. The dynamic strain measurement during the tests at intermediate strain rates was obtained using a non-contact full-field strain measuring system (CSI Vic2D) base on the digital image correlation (DIC) method. A FASTCAMSA 5 high speed camera (Photron, Tokyo, Japan) was used for DIC method, and a random application of dots by marking pens was applied to the sample surface for strain measurement. The whole gauge length was used for the strain measurement by DIC. The detailed description for the dynamic strain measurement can be found elsewhere $[51,52]$.

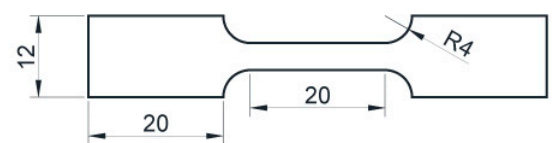

(a)

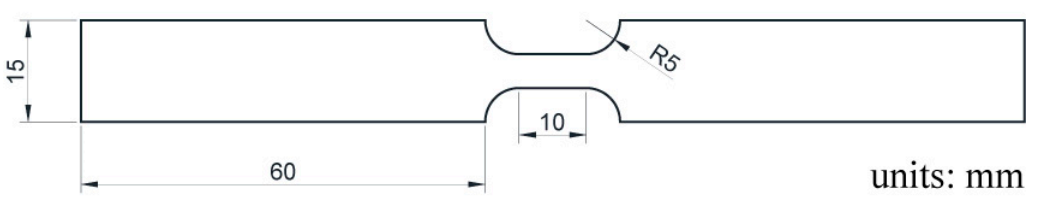

(b)

Figure 1. (a) Shape and dimensions of the dog-bone-shaped tensile specimens for quasi-static tests. (b) Shape and dimensions of the dog-bone-shaped tensile specimens for tensile tests at intermediate strain rate.

\section{Results and Discussion}

The EBSD and TEM images for the microstructures of the HSSS before the tensile tests are shown in Figure $2 a, b$, respectively. The corresponding indexed selected area diffraction pattern for the TEM image is given in the inset of Figure $2 \mathrm{~b}$. After annealing at $900{ }^{\circ} \mathrm{C}$ for $15 \mathrm{~min}$, two phases are clearly visible, in which one is the fcc $\gamma$-austenite with equiaxed recrystallized grains and the other is the B2 phase (FeAl intermetallic compound) with both granular and lamellar shapes. The area fraction of B2 phase is about 22\%. From the TEM image, it can be seen that the B2 phase is much inclined to precipitate at either the grain boundaries or triple junctions of $\gamma$-austenite matrix. Both phases show that they are nearly free of dislocation after annealing at $900{ }^{\circ} \mathrm{C}$ for $15 \mathrm{~min}$, and annealing twins can be clearly seen in the $\gamma$-austenite grain interiors. Both phases show small grains, the average grain size is about $1.65 \mu \mathrm{m}$ for the $\gamma$-austenite phase and is about $0.77 \mu \mathrm{m}$ for the B2 phase.

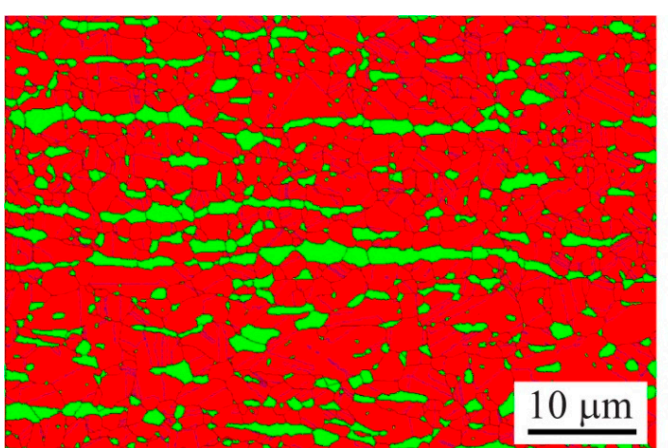

(a)

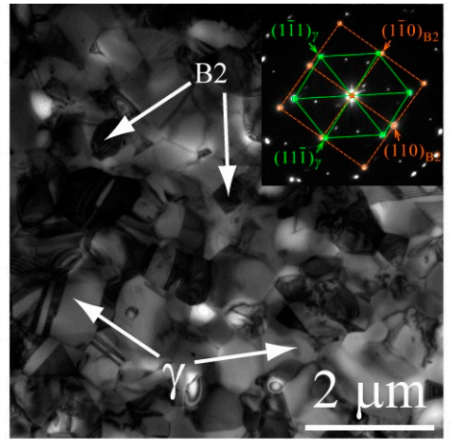

(b)

Figure 2. (a) Electron back-scattered diffraction (EBSD) phase image and grain morphology for the high specific strength steel (HSSS) after annealing at $900{ }^{\circ} \mathrm{C}$ for $15 \mathrm{~min}$ (The red color stands for $\gamma$-austenite phase, and the green color stands for B2 phase). (b) TEM image showing the microstructures of $\gamma$-austenite phase and B2 phase after annealing at $900{ }^{\circ} \mathrm{C}$ for $15 \mathrm{~min}$. The indexed selected area diffraction pattern for TEM image with electron beam closely parallel to both the $[011]_{\gamma}$ and $[001]_{B 2}$ zone axes is shown in the inset of Figure $2 b$. 
The engineering stress-strain curves and the true stress-strain curves for the HSSS at various strain rates are displayed in Figure 3a,b, respectively. The Young's modulus is the same for the experiments conducted at various strain rates. The curves of the strain hardening rate as a function of the true strain are shown in Figure 3c. It is observed that the yield strength and the flow stress increase with increasing strain rate, while the uniform elongation decreases with increasing strain rate. The positive strain rate sensitivity for the yield strength and the flow stress could be due to the following two aspects: (1) Higher flow stress is achieved at higher strain rate since higher strain rate might decelerate the dislocation annihilation; (2) higher strain rate might increase the barriers of dislocation motion for the thermal and mechanically activated plastic deformations [56]. The mechanical properties may be anisotropic in other directions due to the lamellar structure of some B2 grains.

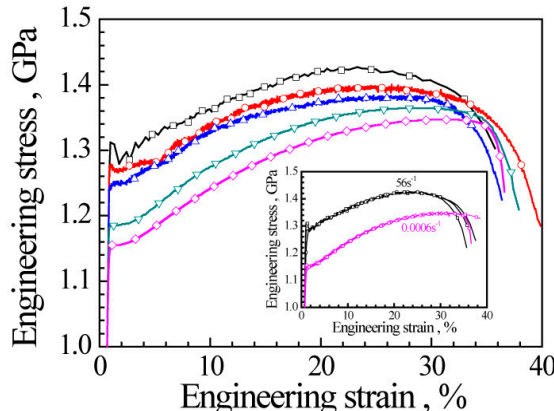

(a)

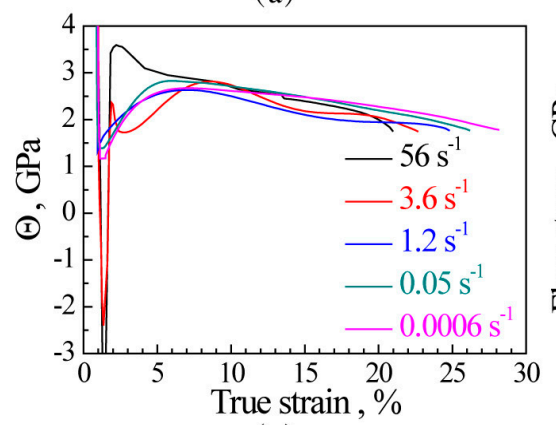

(c)

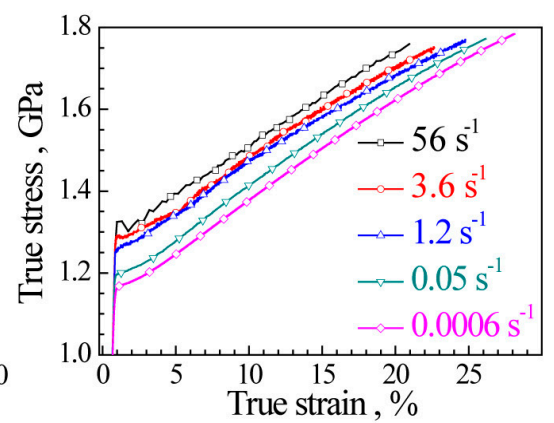

(b)

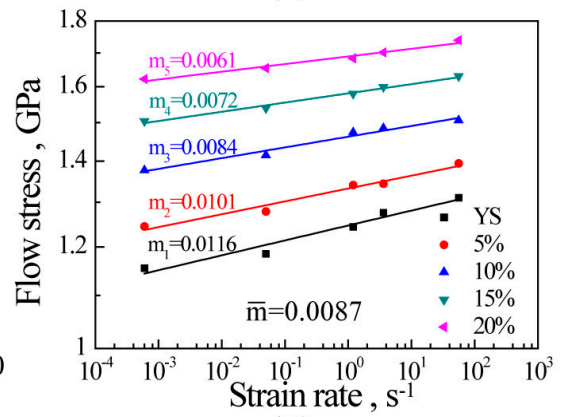

(d)

Figure 3. (a) Engineering stress-strain curves for the HSSS at various strain rates; (b) True stress-strain curves for the HSSS at various strain rates; (c) Strain hardening rate a function of true strain for the HSSS at various strain rates; (d) Yield strength and flow stresses at various true strains as a function of true strain rates in double logarithmic coordinates for the HSSS. The insets of Figure 3a show good repeatability for both tests conducted at quasi-static strain rates and intermediate strain rates.

It is interesting to note that all the stress-strain curves at various strain rates show non-continuous yielding. A concave segment over a range of strains is observed for all the stress-strain curves at various strain rates, and the stress-strain curves show different yielding behaviors at various strain rates. At lower strain rates, a transient deformation stage is observed without yield drop, while at higher strain rates, a yield-peak with yield drop shows up first, followed by a transient deformation stage. As observed in Figure $3 b$ for the strain hardening rate vs. true strain curves, the hardening rate drops rapidly first after yielding, even drops to below zero for the curves with yield drop at higher strain rates, followed by an up-turn to reach its maximum, and then decreases slowly until the necking point. In our previous paper [21], such a transient deformation stage has been found to be caused by the back stress hardening due to the deformation incompatibility between different phases over a strain regime corresponding to the elasto-plastic transition stage. Similar behavior in the hardening rate has also been found recently in the other heterogeneous materials, such as gradient structure [57,58], heterogeneous lamella structure [59] and multilayer laminates [60]. During the plastic deformation of this HSSS, load transfer and strain partitioning between two phases will occur since 
the softer fcc austenite phase are easier to deform than the harder B2 phase. Thus, the softer fcc austenite grains should carry higher plastic strain and lower flow stress during the plastic deformation. The strain rate hardening behaviors and the SRS for the two phases in this HSSS should be quite different, which definitely will affect the magnitude of the strain redistribution between the two phases. This effect of strain rate on the strain partitioning between two phases will be shown and discussed in the following sections.

The SRS of flow stress can be defined as

$$
m=\left(\frac{\partial \ln \sigma}{\partial \ln \dot{\varepsilon}}\right)_{T, \varepsilon}
$$

where $\sigma, \dot{\varepsilon}, \varepsilon, T$ are true stress, true strain rate, true strain and applied temperature, respectively. The yield strength, the true flow stresses at true strains of 5\%,10\%, 15\% and 20\% have plotted in Figure $3 \mathrm{~d}$ as a function of true strain rate in double logarithmic coordinates, and then the average SRS $(\bar{m})$ for this HSSS has been calculated to be about 0.0087 .

The well-known Ludwik's equation [61] can generally be used to describe the strain hardening behaviors of materials and the strain hardening exponent $(n)$ can be obtained from this equation:

$$
\sigma=\sigma_{0}+K \varepsilon^{n}
$$

where $\sigma_{0}$ is the yield strength, and $K$ is the strength coefficient. The uniform elongation, the total elongation and the strain hardening exponent as a function of strain rate are displayed in Figure 4a for this HSSS. The uniform elongation and the strain hardening exponent are observed to decrease with increasing strain rate, while the total elongation remains similar at all strain rates. It is well known that the specific energy absorption under tension can be obtained by integrating the engineering stress over the engineering strain:

$$
W_{s}=\int \sigma_{e} d \varepsilon_{e}
$$

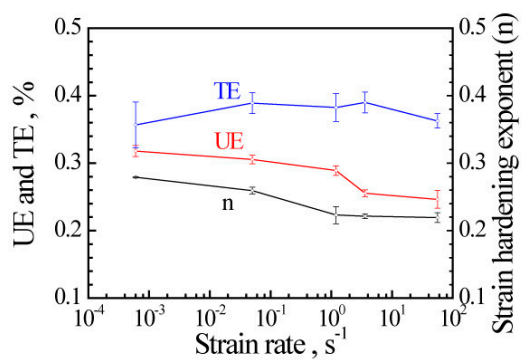

(a)

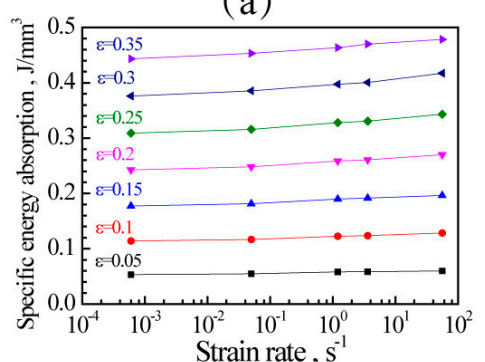

(c)

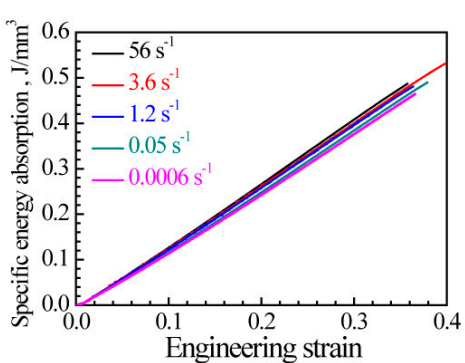

(b)

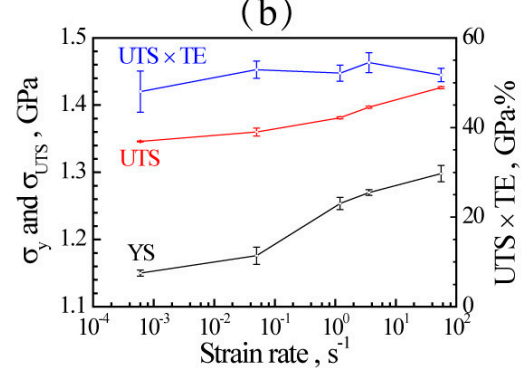

(d)

Figure 4. (a) Uniform elongation, total elongation and strain hardening exponent as a function of strain rate for the HSSS; (b) Specific energy absorption as a function of engineering strain at various strain rates; (c) Specific energy absorption as a function of strain rate at various engineering strains; (d) Yield strength, ultimate strength and tensile toughness as a function of strain rate. 
Thus, the specific energy absorption as a function of engineering strain at various strain rates is plotted in Figure $4 b$, the specific energy absorption as a function of strain rate at various engineering strains is displayed in Figure 4c. It is clearly seen that the specific energy absorption increases with increasing strain rate at various engineering strains due to the positive SRS for this HSSS. The product of the ultimate strength and the total elongation can generally be considered as tensile toughness for materials [53]. Then, the yield strength, the ultimate strength and the tensile toughness are plotted as a function of strain rate in Figure $4 \mathrm{~d}$. It should be noted that the error bars for the standard deviation have been provided in Figure $4 \mathrm{a}, \mathrm{d}$, since three specimens were tested for each data point. Thus, the yield strength, the ultimate strength and the tensile toughness are all observed to increase with increasing strain rate, which indicates both higher strength and higher toughness under tension at higher strain rates. The larger specific energy absorption at higher strain rates is mainly due to the higher flow stress and the similar fracture elongation. It is well known that excellent candidates for energy absorbers require materials that are (i) capable of keeping a high value of the yield strength upon deformation, and (ii) able to absorb more energy up to fracture [30,32]. In addition to the high specific yield strength and the large uniform elongation under quasi-static conditions for this HSSS when compared to the other dual phase steels [11,14,16-19], the simultaneously improved strength and the improved tensile toughness at the intermediate strain rates are very appropriate for the application of this HSSS in the automotive industry to enhance safety during a vehicle crash since the applied strain rate range for vehicle crushing is generally between 1 and 100/s (intermediate strain rates) [51-55] or even higher.

It is well known that the strain and the strain rate have strong influences on the flow stress of metals and alloys [24-28]. A computational model, known as the Johnson-Cook (J-C) model, has been presented for describing all effects of strain hardening, strain rate hardening and thermal softening on the flow stress. This model has been used for different materials including TRIP steels [62] and high strength dual phase steels recently $[63,64]$. This model is quite useful due to its simple expression for engineering applications, and the von Mises flow stress can be expressed as three uncoupled terms as following:

$$
\sigma=\left[A+B \varepsilon_{p}^{n}\right]\left[1+C \ln \dot{\varepsilon}^{*}\right]\left[1-T^{* m}\right]
$$

where $\varepsilon_{p}$ is the true plastic strain, $\dot{\varepsilon}^{*}=\dot{\varepsilon} / \dot{\varepsilon}_{0}$ is the normalized strain rate with respect to $\dot{\varepsilon}_{0}=0.0006 / \mathrm{s}$, and $T^{*}$ is the homologous temperature define as $T^{*}=\left(T-T_{\text {room }}\right) /\left(T_{\text {melt }}-T_{\text {room }}\right) . A, B, C, n, m$ are five material parameters, which need to be determined by fitting the experimental curves. The first term of Equation (4) represents the strain hardening term (usually known as Ludwik equation), which can be determined by the true stress-true strain curve for the test at strain rate of $0.0006 / \mathrm{s}$ (as shown in Figure 5a). The second term of Equation (4) represents the strain rate hardening term, and parameter $C$ is the strain-rate sensitivity. The third term of Equation (4) represents the thermal softening term, which is not within the consideration of the current study. In order to determine parameter $C$, the true flow stresses at four true plastic strains $\left(\varepsilon_{p}=0.05,0.1,0.15,0.2\right)$ were plotted against the logarithmic normalized strain rate in Figure $5 \mathrm{~b}$. The fitting parameters for these experimental data at four true plastic strains were demonstrated as four solid lines in Figure $5 b$, and an average value of parameter $C$ was obtained to be 0.0084 from these four fitting lines. Thus, the J-C model for the flow stress without considering the thermal softening effect can be written as:

$$
\sigma=\left[1.155+2.326 \varepsilon_{p}^{0.991}\right]\left[1+0.0084 \ln \dot{\varepsilon}^{*}\right]
$$

In Equation (5), the constants $A$ (1.155) and B (2.326) have unit of GPa. Based on Equation (5), the hardening J-C model was found to have good agreement with the experimental data for the true stress-true plastic strain curves at various strain rates, as shown in Figure $5 \mathrm{c}$. The maximum possible temperature rise (assuming adiabatic condition) during the plastic tensile deformation can be estimated as $\Delta T=\frac{\eta}{\rho C_{v}} \int \sigma d \varepsilon_{p}$, where $\rho$ is the mass density, $C_{v}$ is the heat capacity, $\eta$ is the Taylor-Quinnery coefficient for plastic work converted to heat (commonly $\eta=0.85$ ), $\varepsilon_{p}$ is the plastic strain, and $\sigma$ is the 
tensile flow stress. For this HSSS, $\rho$ is $6.8 \mathrm{~g} / \mathrm{cm}^{3}$ and $C_{v}$ can be approximately taken as $540 \mathrm{~J} / \mathrm{kg}$ [65]. Thus, Equation (5) can be used to well describe the flow behaviors of this HSSS up to strain rate of 56/s since the possible temperature rise by the dissipated plastic work in the specimen is less than $80^{\circ} \mathrm{C}$ (calculation based on above equation) for the test at strain rate of 56/s. Moreover, the application of this HSSS at even higher strain rates requires in-depth study on the relation between the temperature and the flow stress in the future work since the adiabatic temperature rise during high strain rate tension is inevitable and the thermal softening should be considered.

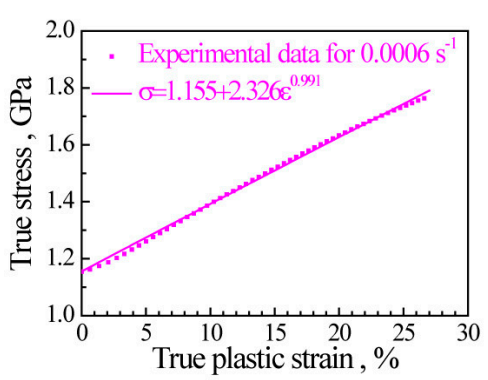

(a)

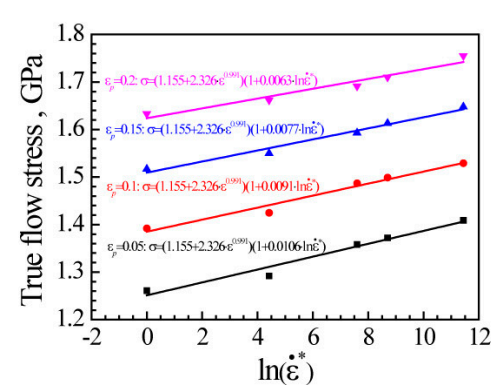

(b)

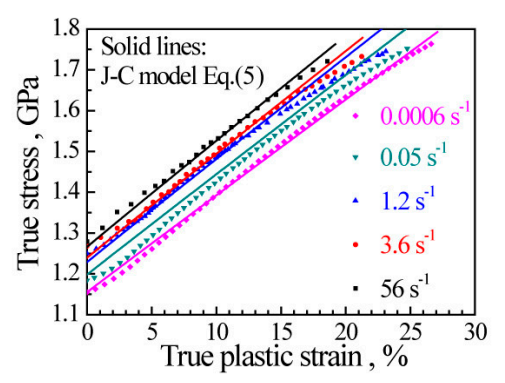

(c)

Figure 5. (a) Experimental data for true stress-true plastic strain curve at strain rate of 0.0006/s and the fitting curve of the J-C model; (b) True flow stress as a function of logarithmic normalized strain rate at various true plastic strains; (c) Comparison for true stress-true plastic strain curves between the experimental data and the $\mathrm{J}-\mathrm{C}$ model.

In our recent paper [66], significant phase transformation from fcc austenite phase to B2 phase by diffusional transformation has been observed to facilitate the superplasticity during the tensile testing under temperature of $973 \mathrm{~K}$ for this HSSS. The high temperature $(973 \mathrm{~K})$ can facilitate the diffusional behaviors of the elements and the diffusional transformation. The EBSD phase distributions after tensile tests at various strain rates under room temperature are displayed in Figure 6a-e, and the volume fraction of B2 phase after tensile testing as a function of the applied tensile strain rate is shown in Figure 6f. As indicated, the volume fractions of B2 phase after tensile tests at various strain rates $(\sim 22 \%)$ are very similar to that of the untested sample $(\sim 22 \%)$, indicating that no phase transformation is observed at all strain rates. These observations indicate that the fcc austenite phase is relatively stable under room temperature even at intermediate strain rates since the diffusional transformation cannot occur at these stresses and strain rates without the assistance of high temperature. Thus, the plastic deformation during tensile tests at various strain rates under room temperature should be accommodated by the deformation twins and the dislocation behaviors in both phases, which will be illustrated by TEM observations later. 


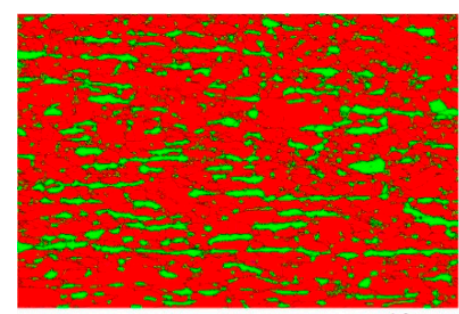

(a)

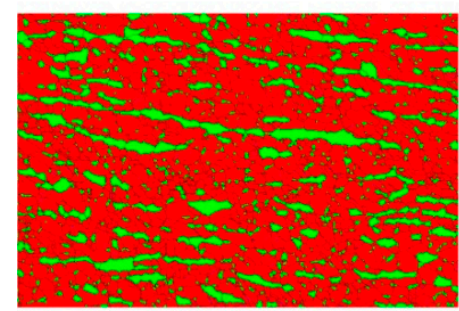

(d)

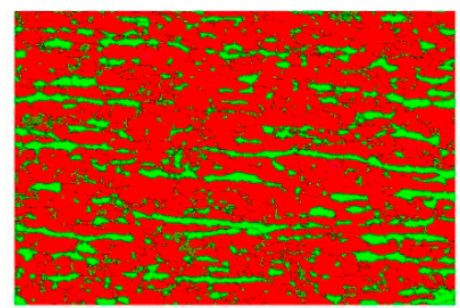

(b)

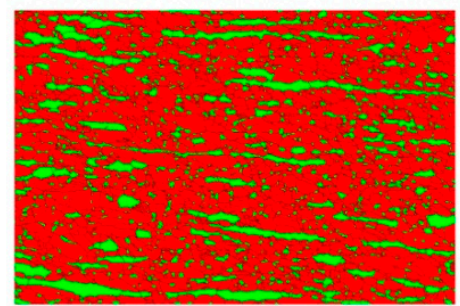

(e)

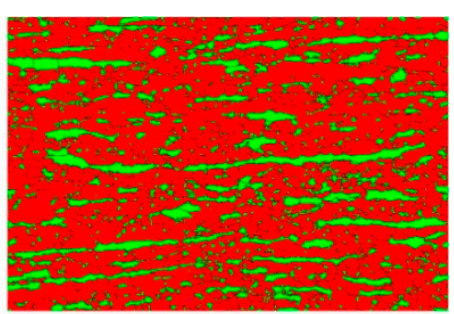

(c)

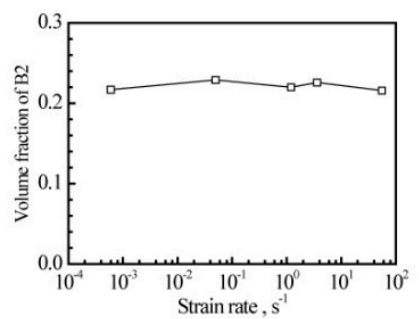

(f)

Figure 6. EBSD phase distributions after testing at strain rate of (a) $0.0006 / \mathrm{s}$; (b) $0.05 / \mathrm{s}$; (c) $1.2 / \mathrm{s}$; (d) 3.6/s; (e) 56/s. The red color stands for $\gamma$-austenite phase, and the green color stands for B2 phase.

(f) The volume fraction of $\mathrm{B} 2$ phase after tensile testing versus the applied tensile strain rate.

In this HSSS, the $\gamma$-austenite phase is softer than the B2 phase, thus the strain partitioning makes the $\gamma$-austenite grains to bear larger amount of plastic strains. The back stress hardening has been found to play an important role for the tensile ductility in this HSSS due to the load transfer and the strain partitioning between two phases [21]. This strain partitioning is measured by the aspect ratio changes before and after tensile tests at two different strain rates $(0.0006$ and 56/s) for this HSSS. The grain morphologies for $\gamma$-austenite grains before tensile tests are displayed in Figure $7 \mathrm{a}$, while the grain morphologies for $\gamma$-austenite grains after tensile tests at two strain rates $(0.0006$ and $56 / \mathrm{s})$ are shown in Figure $7 \mathrm{~b}, \mathrm{c}$ (the tensile direction is along the horizontal direction). The corresponding aspect ratio information before and after tensile tests is displayed in Figure $7 \mathrm{~d}-\mathrm{f}$. In these figures, $\bar{l}$ and $\bar{w}$ indicate the average spacing in axial and transverse directions, $\bar{\alpha}$ is the average aspect ratio defined by $\bar{\alpha}=\bar{l} / \bar{w}$. In Figure $7 \mathrm{~b}, \mathrm{c}$, the EBSD images correspond to the true uniform tensile strains of $28.1 \%$ and $20.9 \%$ (as shown in Figure $3 b$ ), respectively. As indicated, most of the initial, relatively equi-axed $\gamma$-austenite grains now become strongly elongated along the tensile direction. Then, the mean true strain in the $\gamma$-austenite grains can be estimated, and the details for the derivation of the formula and the calculation method can be found in our previous paper [59]. Basically, by assuming the volume is constant during the plastic deformation, the tensile true strain is estimated based on the aspect ratio change after the tensile deformation. Then, the mean true tensile strains experienced by the $\gamma$-austenite grains during the uniform tensile loading at the strain rates of 0.0006 and $56 / \mathrm{s}$ can be estimated to be $31.5 \%$ and $24.0 \%$, respectively. Based on the rule of mixture, the mean true tensile strains experienced by the $\mathrm{B} 2$ phase during the uniform tensile loading at the strain rates of 0.0006 and $56 / \mathrm{s}$ can be calculated to be $16.0 \%$ and $9.9 \%$, respectively. Then, the ratio of strains between fcc austenite phase and B2 phase at the strain rate of $0.0006 / \mathrm{s}$ is estimated to be about 1.97 , while the ratio of strains between fcc austenite phase and B2 phase at the strain rate of $56 / \mathrm{s}$ is estimated to be about 2.42. The data for strain partitioning between two phases at two different strain rates can be summarized in Table 1. It is observed that the softer fcc austenite grains even bear a higher fraction of true tensile strain at higher strain rates. It is well known that the SRS for the fcc $\gamma$-austenite and the hard B2 phase should be quite different. It is highly possible that the SRS of the fcc $\gamma$-austenite is higher than that of the B2 phase, making the fcc $\gamma$-austenite to accommodate more fraction of strain at higher strain rates. It is well accepted that the tensile elongation is generally much smaller at high strain rates due to the adiabatic temperature rise under dynamic loading $[23,27,28]$, while the total 
tensile elongation is similar at all strain rates in the present study, which could be due to the fact that the softer fcc $\gamma$-austenite grains with high deformation ability bear more fraction of strain, which delays the deformation instability and the crack initiation for the B2 phase and the phase interfaces.

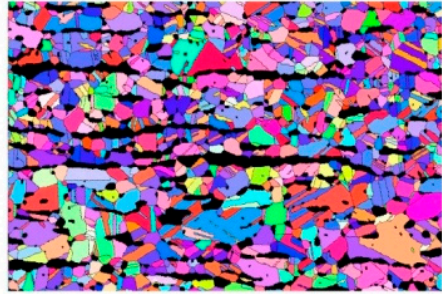

(a)

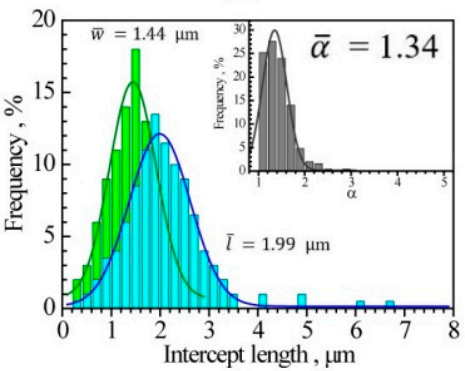

(d)

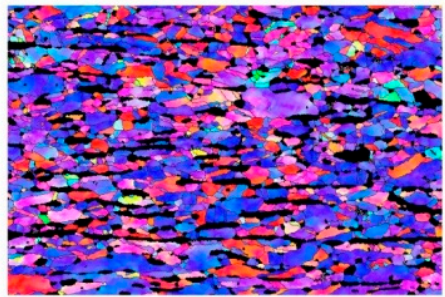

(b)

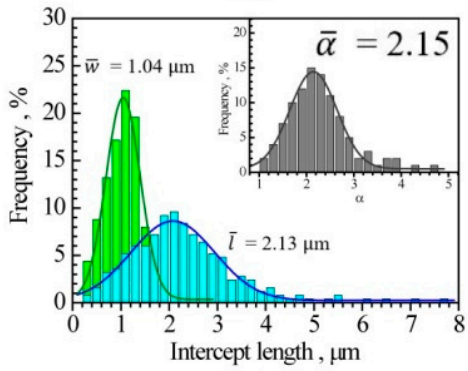

(e)

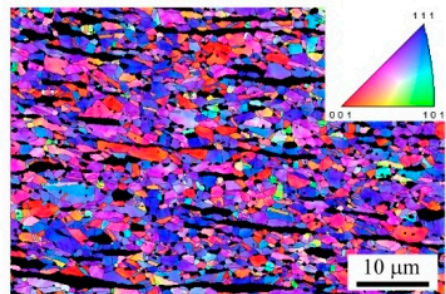

(c)

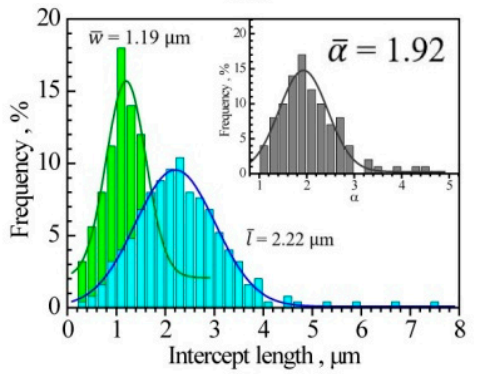

(f)

Figure 7. EBSD images and grain morphologies of $\gamma$-austenite phase for (a) untested sample; (b) sample after testing at strain rate of $0.0006 / \mathrm{s}$; (c) sample after testing at strain rate of 56/s. The EBSD images correspond to the true uniform tensile strains of $28.1 \%$ (Figure $7 \mathrm{a}$ ) and $20.9 \%$ (Figure $7 \mathrm{~b}$ ). Histograms showing the statistics of the grain size distribution and aspect ratio measurements for: (d) untested sample; (e) sample after testing at strain rate of 0.0006/s; (f) sample after testing at strain rate of 56/s.

Table 1. Summary of data for strain partitioning between two phases at two different strain rates.

\begin{tabular}{ccccccc}
\hline Strain Rates (/s) & $\begin{array}{c}\text { Uniform Elongation } \\
\left(\varepsilon_{u}\right)\end{array}$ & $\varepsilon_{\gamma}$ & $\varepsilon_{\boldsymbol{B}_{2}}$ & $\begin{array}{c}\text { Fraction of Strain } \\
\left(f_{\gamma} \varepsilon_{\gamma} / \varepsilon_{u}\right)\end{array}$ & $\begin{array}{c}\text { Fraction of Strain } \\
\left(f_{\boldsymbol{B}_{2}} \varepsilon_{\boldsymbol{B}_{2}} / \varepsilon_{u}\right)\end{array}$ & $\begin{array}{c}\text { Ratio of Strains } \\
\left(\varepsilon_{\gamma} / \varepsilon_{\boldsymbol{B}_{2}}\right)\end{array}$ \\
\hline 0.0006 & $28.1 \%$ & $31.5 \%$ & $16.0 \%$ & $87.4 \%$ & $12.6 \%$ & 1.97 \\
56 & $20.9 \%$ & $24.0 \%$ & $9.9 \%$ & $89.6 \%$ & $10.4 \%$ & 2.42 \\
\hline
\end{tabular}

In order to illustrate the strain rate effect on the strain partitioning and the deformation mechanisms, the TEM images for the samples after testing at strain rates of $0.0006 / \mathrm{s}$ and $56 / \mathrm{s}$ are displayed in Figure 8. As indicated, a high density of deformation twins (even occasional multiple twins, marked by primary twins as first and secondary twins as second) and dislocations in the grain interiors of fcc austenite phase are observed at both low and high strain rates. The fcc austenite grains are observed to be stretched to true strains of $31.5 \%$ and $24.0 \%$ at strain rates of 0.0006 and $56 / \mathrm{s}$, and these high plastic deformations are expected to increase the dislocation density and the deformation twins in the grain interiors of fcc austenite grains. These formed twin boundaries (TBs) by deformation twins are effective obstacles to the motion of dislocations and can accumulate the pile-up of dislocations near TBs (as indicated in Figure 8), which could provide great resistance to the further dislocation motion and thus the strong strain hardening for sustaining uniform elongation as suggested by previous research [4]. Dislocations are also observed in the B2 grains after tensile testing, indicating that the B2 phase are plastically deformable and the dislocations can be stored in the B2 grains. As indicated, high density of dislocations are also observed to accumulate around the B2 particles and these high density of dislocations at the phase interfaces will ensure the continuous strains at the phase interfaces to accommodate the strain gradient between the two phases and to elevate the back stress [21]. 


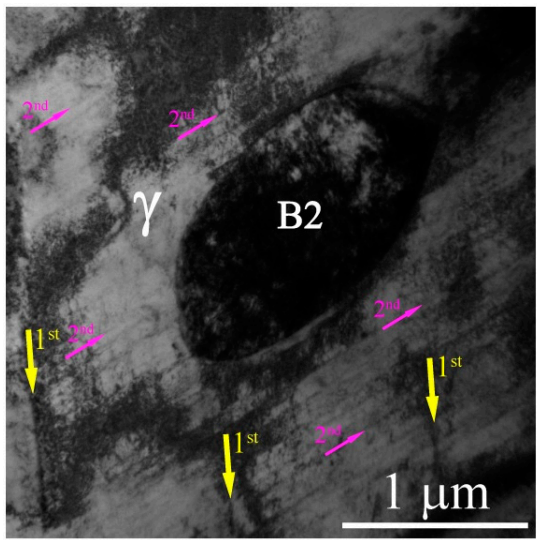

(a)

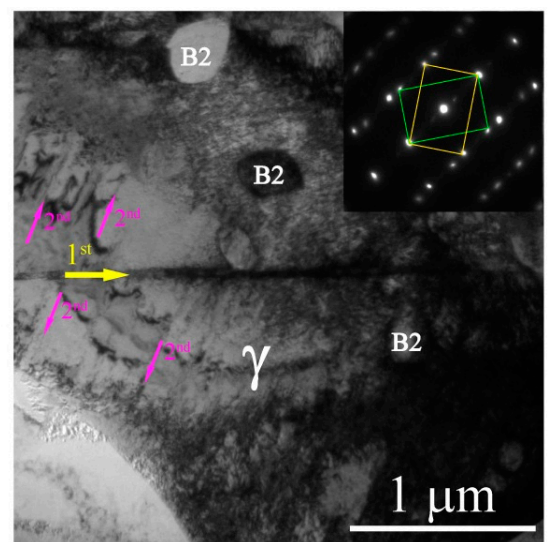

(b)

Figure 8. TEM images for (a) sample after testing at strain rate of $0.0006 / \mathrm{s}$; (b) sample after testing at strain rate of $56 / \mathrm{s}$.

The SEM images of final fracture surfaces for the tensile tests at various strain rates are shown in Figure 9. The tensile fracture at various strain rates is observed to be ductile with dimples. The average dimple size is estimated to be $3.22,2.96,1.63,1.44,1.37 \mu \mathrm{m}$ for the tensile tests at strain rates of 0.0006 , $0.05,1.2,3.6,56 / \mathrm{s}$ based on the SEM images. These dimples appear to be formed by pulling the $\mathrm{B} 2$ grains out from the fcc austenite matrix or fracturing the B2 particle during the tensile loading. As indicated earlier, the B2 phase is less deformable at higher strain rates, which result in easier brittle fracture in B2 particles and smaller dimple size at the final fracture surface. Thus, the size of B2 particles will be smaller and the density of the phase interfaces will be higher at the final fracture surfaces, and more energy is needed to consume for the final fracture at higher strain rates due to the fracturing of B2 phase during the tensile deformation at higher strain rates. These observations could also provide the origin for the higher energy absorption during the tensile deformation at higher strain rates, as shown in Figure 4.

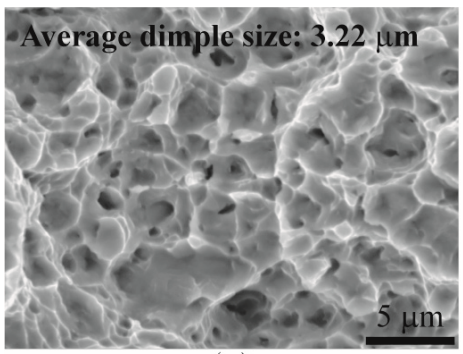

(a)

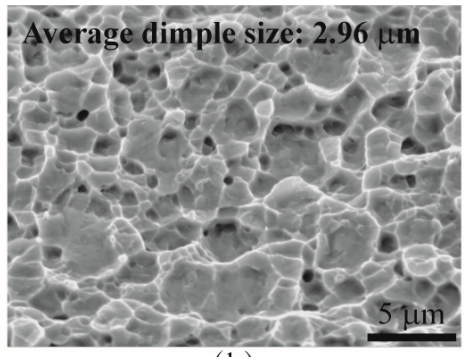

(b)

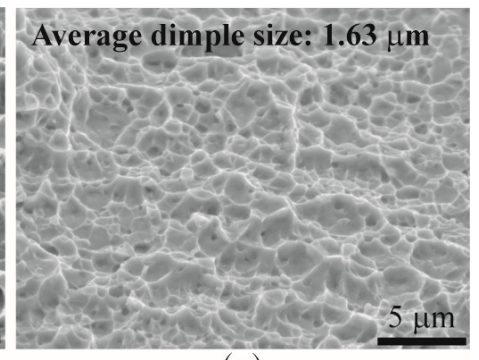

(c)

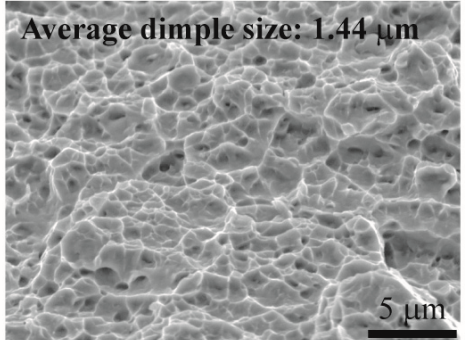

(d)

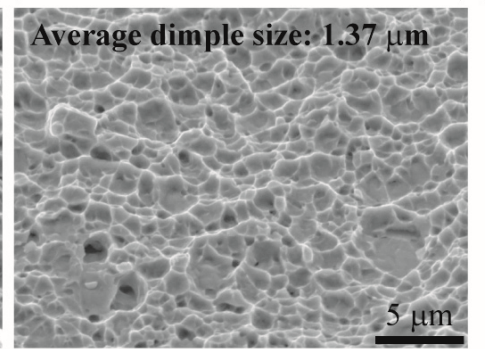

(e)

Figure 9. SEM images of the fracture surfaces for the tensile tests at various strain rates: (a) 0.0006/s; (b) $0.05 / \mathrm{s}$; (c) $1.2 / \mathrm{s}$; (d) $3.6 / \mathrm{s}$; (e) $56 / \mathrm{s}$. 


\section{Conclusions}

The tensile behaviors of the HSSS with ultrafine grains and dual-phase microstructure were investigated over a wide range of strain rates from 0.0006 to 56/s in the present study, and the main findings are summarized as follows:

(1) This HSSS shows excellent tensile properties at the strain rate range of 0.0006 to $56 / \mathrm{s}$. The uniform elongation and the strain hardening exponent are observed to decrease slightly with increasing strain rate for this HSSS, while it is observed that the yield strength, the ultimate tensile strength and the tensile toughness all increase with increasing strain rate at the strain rate range from 0.0006 to 56/s, rendering this HSSS as an excellent candidate for energy absorber in automobile industry.

(2) The Johnson-Cook model can be used to well describe the strain hardening behaviors and the strain rate effect for this HSSS, and the final constitutive relation has the form of $\sigma=\left[1.155+2.326 \varepsilon_{p}^{0.991}\right]\left[1+0.0084 \ln \dot{\varepsilon}^{*}\right]$ and has a good agreement with experimental results.

(3) At lower strain rates, a transient strain hardening behavior is observed without yield drop, while at higher strain rates a yield-peak with yield drop shows up first, followed by a transient deformation stage. Such a transient deformation stage has been found to be caused by the back stress hardening due to the load transfer and strain partitioning between two phases, and the softer fcc austenite grains even bear more fraction of true tensile strain to delay the deformation instability at higher strain rates. No phase transformation is observed at all strain rates. The deformation twins are observed in the fcc austenite grains at all strain rates, facilitating the uniform tensile deformation.

(4) The dimple size is observed to be smaller and the density of phase interfaces is found to be higher at final fracture surfaces, and thus more energy need be consumed during the final fracture for the experiments conducted at higher strain rates, resulting in better tensile toughness at higher strain rates. This higher density of the phase interfaces can be attributed to the easier brittle fracture in B2 particles since the B2 phase is less deformable at higher strain rates. The present results should provide insights for better understanding the deformation physics of this HSSS and provide design strategy for achieving better mechanical properties for impact-tolerant applications in automobile industry. In future work, the compressive properties of this HSSS at various strain rates should also be investigated for better understanding in applications as energy absorbers.

Acknowledgments: This work was supported by National Key R\&D Program of China [Grant number 2017YFA0204402]; NSFC [Grant numbers 11672313, 11472286, 11572328, 51701228, and 51601204]; and the Strategic Priority Research Program of the Chinese Academy of Sciences [Grant number XDB22040503]. The authors would like to thank Yang Liu from Northeastern University (China) for helping to conduct the mechanical testing.

Author Contributions: Fuping Yuan and Xiaolei Wu conceived and designed the experiments; Muxin Yang provided the materials; Wei Wang performed the mechanical testing; Wei Wang, Yan Ma and Ping Jiang conducted the microstructure characterization; Fuping Yuan and Wei Wang wrote the paper.

Conflicts of Interest: The authors declare no conflict of interest.

\section{References}

1. Fischer, F.D.; Reisner, G.; Werner, E.; Tanaka, K.; Cailletaud, G.; Antretter, T. A new view on transformation induced plasticity (TRIP). Int. J. Plast. 2000, 16, 723-748. [CrossRef]

2. Grässel, O.; Krüger, L.; Frommeyer, G.; Meyer, L.W. High strength Fe-Mn-(Al, Si) TRIP/TWIP steels development-properties-application. Int. J. Plast. 2000, 16, 1391-1409. [CrossRef]

3. Frommeyer, G.; Brüx, U.; Neumann, P. Supra-ductile and high-strength manganese-TRIP/TWIP steels for high energy absorption purposes. ISIJ Int. 2003, 43, 438-446. [CrossRef]

4. Bouaziz, O.; Allain, S.; Scott, C. Effect of grain and twin boundaries on the hardening mechanisms of twinning-induced plasticity steels. Scr. Mater. 2008, 58, 484-487. [CrossRef]

5. Kang, S.; Jung, Y.S.; Jun, J.H.; Lee, Y.K. Effects of recrystallization annealing temperature on carbide precipitation, microstructure, and mechanical properties in Fe-18Mn-0.6C-1.5Al TWIP steel. Mater. Sci. Eng. A 2010, 527, 745-751. [CrossRef] 
6. Son, Y.I.; Lee, Y.K.; Park, K.T.; Lee, C.S.; Shin, D.H. Ultrafine grained ferrite-martensite dual phase steels fabricated via equal channel angular pressing: Microstructure and tensile properties. Acta Mater. 2005, 53, 3125-3134. [CrossRef]

7. Calcagnotto, M.; Adachi, Y.; Ponge, D.; Raabe, D. Deformation and fracture mechanisms in fine-and ultrafine-grained ferrite/martensite dual-phase steels and the effect of aging. Acta Mater. 2011, 59, 658-670. [CrossRef]

8. Jiang, S.H.; Wang, H.; Wu, Y.; Liu, X.J.; Chen, H.H.; Yao, M.J.; Gault, B.; Ponge, D.; Raabe, D.; Hirata, A.; et al. Ultrastrong steel via minimal lattice misfit and high-density nanoprecipitation. Nature 2017, 544, 460-464. [CrossRef] [PubMed]

9. Raabe, D.; Springer, H.; Gutierrez-Urrutia, I.; Roters, F.; Bausch, M.; Seol, J.B.; Koyama, K.; Choi, P.P.; Tsuzaki, K. Alloy design, combinatorial synthesis, and microstructure-property relations for low-density Fe-Mn-Al-C austenitic steels. JOM 2014, 66, 1845-1856. [CrossRef]

10. Raabe, D.; Tasan, C.C.; Springer, H.; Bausch, M. From high-entropy alloys to high-entropy steels. Steel Res. Int. 2015, 86, 1127-1138. [CrossRef]

11. Frommeyer, G.; Bruex, U. Microstructures and mechanical properties of high strength $\mathrm{Fe}-\mathrm{Mn}-\mathrm{Al}-\mathrm{C}$ light-weight TRIPLEX steels. Steel Res. Int. 2006, 77, 627-633. [CrossRef]

12. Rana, R.; Lahaye, C.; Ray, R.K. Overview of lightweight ferrous materials: Strategies and promises. JOM 2014, 66, 1734-1746. [CrossRef]

13. Kim, H.; Suh, D.W.; Kim, N.J. Fe-Al-Mn-C lightweight structural alloys: A review on the microstructures and mechanical properties. Sci. Technol. Adv. Mater. 2013, 14, 014205. [CrossRef] [PubMed]

14. Sohn, S.S.; Song, H.; Suh, B.C.; Kwak, J.H.; Lee, B.J.; Kim, N.J.; Lee, S. Novel ultra-high-strength (ferrite + austenite) duplex lightweight steels achieved by fine dislocation substructures (Taylor lattices), grain refinement, and partial recrystallization. Acta Mater. 2015, 96, 301-310. [CrossRef]

15. Gutierrez-Urrutia, I.; Raabe, D. Multistage strain hardening through dislocation substructure and twinning in a high strength and ductile weight-reduced Fe-Mn-Al-C steel. Acta Mater. 2012, 60, 5791-5802. [CrossRef]

16. Gutierrez-Urrutia, I.; Raabe, D. Influence of Al content and precipitation state on the mechanical behavior of austenitic high-Mn low-density steels. Scr. Mater. 2013, 68, 343-347. [CrossRef]

17. Yoo, J.D.; Hwang, S.W.; Park, K.T. Factors influencing the tensile behavior of a Fe-28Mn-9Al-0.8C steel. Mater. Sci. Eng. A 2009, 508, 234-240. [CrossRef]

18. Hwang, S.W.; Ji, J.H.; Lee, E.G.; Park, K.T. Tensile deformation of a duplex Fe-20Mn-9Al-0.6C steel having the reduced specific weight. Mater. Sci. Eng. A 2011, 528, 5196-5203. [CrossRef]

19. Wu, Z.Q.; Ding, H.; An, X.H.; Han, D.; Liao, X.Z. Influence of Al content on the strain-hardening behavior of aged low density Fe-Mn-Al-C steels with high Al content. Mater. Sci. Eng. A 2015, 639, 187-191. [CrossRef]

20. Kim, S.H.; Kim, H.; Kim, N.J. Brittle intermetallic compound makes ultrastrong low-density steel with large ductility. Nature 2015, 518, 77-79. [CrossRef] [PubMed]

21. Yang, M.X.; Yuan, F.P.; Xie, Q.G.; Wang, Y.D.; Ma, E.; Wu, X.L. Strain hardening in Fe-16Mn-10Al-0.86C-5Ni high specific strength steel. Acta Mater. 2016, 109, 213-222. [CrossRef]

22. Wang, W.; Zhang, H.S.; Yang, M.X.; Jiang, P.; Yuan, F.P.; Wu, X.L. Shock and spall behaviors of a high specific strength steel: Effects of impact stress and microstructure. J. Appl. Phys. 2017, 121, 135901. [CrossRef]

23. Nemat-Nasser, S.; Guo, W.G. Thermomechanical response of DH-36 structural steel over a wide range of strain rates and temperatures. Mech. Mater. 2003, 35, 1023-1047. [CrossRef]

24. Mishra, A.; Martin, M.; Thadhani, N.N.; Kad, B.K.; Kenik, E.A.; Meyers, M.A. High-strain-rate response of ultra-fine-grained copper. Acta Mater. 2008, 56, 2770-2783. [CrossRef]

25. Wei, Q. Strain rate effects in the ultrafine grain and nanocrystalline regimes-Influence on some constitutive responses. J. Mater. Sci. 2007, 42, 1709-1727. [CrossRef]

26. Subhash, G. The constitutive behavior of refractory-metals as a function of strain-rate. JOM 1995, 5, 55-58. [CrossRef]

27. Suo, T.; Li, Y.L.; Zhao, F.; Fan, X.L.; Guo, W.G. Compressive behavior and rate-controlling mechanisms of ultrafine grained copper over wide temperature and strain rate ranges. Mech. Mater. 2013, 61, 1-10. [CrossRef]

28. Suo, T.; Chen, Y.Z.; Li, Y.L.; Wang, C.X.; Fan, X.L. Strain rate sensitivity and deformation kinetics of ECAPed aluminum over a wide range of strain rates. Mater. Sci. Eng. A 2013, 560, 545-551. [CrossRef] 
29. Wei, Q.; Kecskes, L.; Jiao, T.; Hartwig, K.T.; Ramesh, K.T.; Ma, E. Adiabatic shear banding in ultrafine-grained Fe processed by severe plastic deformation. Acta Mater. 2004, 52, 1859-1869. [CrossRef]

30. Xue, Q.; Gray, G.T., III; Henrie, B.L.; Maloy, S.A.; Chen, S.R. Influence of shock prestraining on the formation of shear localization in 304 stainless steel. Metall. Mater. Trans. A 2005, 36, 1471-1486. [CrossRef]

31. Yang, Y.; Jiang, F.; Zhou, B.M.; Li, X.M.; Zheng, H.G.; Zhang, Q.M. Microstructural characterization and evolution mechanism of adiabatic shear band in a near beta-Ti alloy. Mater. Sci. Eng. A 2011, 528, 2787-2794. [CrossRef]

32. Yuan, F.P.; Jiang, P.; Wu, X.L. Annealing effect on the evolution of adiabatic shear band under dynamic shear loading in ultra-fine-grained iron. Int. J. Impact Eng. 2012, 50, 1-8. [CrossRef]

33. Yuan, F.P.; Bian, X.D.; Jiang, P.; Yang, M.X.; Wu, X.L. Dynamic shear response and evolution mechanisms of adiabatic shear band in an ultrafine-grained austenite-ferrite duplex steel. Mech. Mater. 2015, 89, 47-58. [CrossRef]

34. Yuan, F.P.; Chen, P.; Feng, Y.P.; Jiang, P.; Wu, X.L. Strain hardening behaviors and strain rate sensitivity of gradient-grained Fe under compression over a wide range of strain rates. Mech. Mater. 2016, 95, 71-82. [CrossRef]

35. Singh, N.K.; Cadoni, E.; Singha, M.K.; Gupta, N.K. Dynamic tensile behavior of multi phase high yield strength steel. Mater. Des. 2011, 32, 5091-5098. [CrossRef]

36. Xiong, R.G.; Fu, R.Y.; Su, Y.; Li, Q.; Wei, X.C.; Li, L. Tensile Properties of TWIP Steel at High Strain Rate. J. Iron Steel Res. Int. 2009, 16, 81-86. [CrossRef]

37. Boyce, B.L.; Dilmore, M.F. The dynamic tensile behavior of tough, ultrahigh-strength steels at strain-rates from $0.0002 \mathrm{~s}^{-1}$ to $200 \mathrm{~s}^{-1}$. Int. J. Impact Eng. 2009, 36, 263-271. [CrossRef]

38. Cadoni, E.; Singh, N.K.; Forni, D.; Singha, M.K.; Gupta, N.K. Strain rate effects on the mechanical behavior of two Dual Phase steels in tension. Eur. Phys. J. Spec. Top. 2016, 225, 409-421. [CrossRef]

39. Geiger, M.; Merklein, M.; Kaupper, M. Investigation of the mechanical behaviour of advanced high strength steels under various loading conditions. Int. J. Mater. Form. 2008, 1, 225-228. [CrossRef]

40. Yu, H.D.; Guo, Y.J.; Lai, X.M. Rate-dependent behavior and constitutive model of DP600 steel at strain rate from $10^{-4}$ to $10^{3} \mathrm{~s}^{-1}$. Mater. Des. 2009, 30, 2501-2505. [CrossRef]

41. Das, A.; Tarafder, S. Experimental investigation on martensitic transformation and fracture morphologies of austenitic stainless steel. Int. J. Plast. 2009, 25, 2222-2247. [CrossRef]

42. Lee, S.; Estrin, Y.; De Cooman, B. Effect of the strain rate on the TRIP-TWIP transition in austenitic Fe-12 pct Mn-0.6 pct C TWIP steel. Mater. Trans. A 2014, 45, 717-730. [CrossRef]

43. Zaera, R.; Rodríguez-Martínez, J.A.; Vadillo, G.; Fernández-Sáez, J. Dynamic necking in materials with strain induced martensitic transformation. J. Mech. Phys. Solids 2014, 64, 316-337. [CrossRef]

44. Gu, Z.W.; Jin, X.G.; Gao, G.Q. Shock response of stainless steel at high temperature. J. Mater. Sci. 2000, 35, 2347-2351. [CrossRef]

45. Gray, G.T., III; Livescu, V.; Rigg, P.A.; Trujillo, C.P.; Cady, C.M.; Chen, S.R.; Carpenter, J.S.; Lienert, T.J.; Fensin, S. Structure/property (constitutive and dynamic strength/damage) characterization of additively manufactured 316L SS. EPJ Web Conf. 2015, 94, 02006. [CrossRef]

46. Savinykh, A.S.; Garkushin, G.V.; Razorenov, S.V.; Wolf, S.; Kruger, L. Influence of the temperature-induced martensitic-austenitic transformation on the strength properties of high-alloy steels under dynamic loading. Combust. Explos. Shock Waves 2015, 51, 124-129. [CrossRef]

47. Tarigopula, V.; Hopperstad, O.S.; Langseth, M.; Clausen, A.H.; Hild, F. A study of localization in dual-phase high-strength steels under dynamic loading using digital image correlation and FE analysis. Int. J. Solids Struct. 2008, 45, 601-619. [CrossRef]

48. Wang, W.R.; Li, M.; He, C.W.; Wei, X.C.; Wang, D.Z.; Du, H.B. Experimental study on high strain rate behavior of high strength 600-1000 MPa dual phase steels and $1200 \mathrm{MPa}$ fully martensitic steels. Mater. Des. 2013, 47, 510-521. [CrossRef]

49. Qin, J.G.; Chen, R.; Wen, X.J.; Lin, Y.L.; Liang, M.Z.; Lu, F.Y. Mechanical behaviour of dual-phase high-strength steel under high strain rate tensile loading. Mater. Sci. Eng. A 2013, 586, 62-70. [CrossRef]

50. Moćko, W.; Brodecki, A.; Kruszka, L. Mechanical response of dual phase steel at quasi-static and dynamic tensile loadings after initial fatigue loading. Mech. Mater. 2016, 92, 18-27. [CrossRef]

51. Dong, D.Y.; Liu, Y.; Yang, Y.L.; Li, J.F.; Ma, M.; Jiang, T. Microstructure and dynamic tensile behavior of DP600 dual phase steel joint by laser welding. Mater. Sci. Eng. A 2014, 594, 17-25. [CrossRef] 
52. Liu, Y.; Dong, D.Y.; Wang, L.; Chu, X.; Wang, P.F.; Jin, M.M. Strain rate dependent deformation and failure behavior of laser welded DP780 steel joint under dynamic tensile loading. Mater. Sci. Eng. A 2015, 627, 296-305. [CrossRef]

53. Meyers, M.A. Dynamic Behavior of Materials; John Wiley \& Sons: Hoboken, NJ, USA, 1994.

54. Xu, S.Q.; Ruan, D.; Beynon, J.H.; Rong, Y.H. Dynamic tensile behaviour of TWIP steel under intermediate strain rate loading. Mater. Sci. Eng. A 2013, 573, 132-140. [CrossRef]

55. Oliver, S.; Jones, T.B.; Fourlaris, G. Dual phase versus TRIP strip steels: Comparison of dynamic properties for automotive crash performance. Mater. Sci. Technol. 2007, 23, 423-431. [CrossRef]

56. Huh, H.; Kim, S.B.; Song, J.H.; Lim, J.H. Dynamic tensile characteristics of TRIP-type and DP-type steel sheets for an auto-body. Int. J. Mech. Sci. 2008, 50, 918-931. [CrossRef]

57. Wu, X.L.; Jiang, P.; Chen, L.; Yuan, F.P.; Zhu, Y.T. Extraordinary strain hardening by gradient structure. Proc. Natl. Acad. Sci. USA 2014, 111, 7197-7201. [CrossRef] [PubMed]

58. Yang, M.X.; Pan, Y.; Yuan, F.P.; Zhu, Y.T.; Wu, X.L. Back stress strengthening and strain hardening in gradient structure. Mater. Res. Lett. 2016, 4, 141-151. [CrossRef]

59. Wu, X.L.; Yang, M.X.; Yuan, F.P.; Wu, G.L.; Wei, Y.J.; Huang, X.X.; Zhu, Y.T. Heterogeneous lamella structure Unites ultrafine-grain strength with coarse grain ductility. Proc. Natl. Acad. Sci. USA 2015, 112, 14501-14505. [CrossRef] [PubMed]

60. Ma, X.L.; Huang, C.X.; Moering, J.; Ruppert, M.; Höppel, H.W.; Göken, M.; Narayan, J.; Zhu, Y.T. Mechanical properties of copper/bronze laminates: Role of interfaces. Acta Mater. 2016, 116, 43-52. [CrossRef]

61. Sung, J.H.; Kim, J.H.; Wagoner, R.H. A plastic constitutive equation incorporating strain, strain-rate, and temperature. Int. J. Plast. 2010, 26, 1746-1771. [CrossRef]

62. Van Slycken, J.; Verleysen, P.; Degrieck, J.; Bouquerel, J. Constitutive equations for multiphase TRIP steels at high rates of strain. J. Phys. IV 2006, 134, 69-74. [CrossRef]

63. Vedantam, K.; Bajaj, D.; Brar, N.S.; Hill, S. Johnson-Cook strength models for mild and DP 590 steels. AIP Conf. Proc. 2006, 845, 775-778.

64. Roth, C.C.; Mohr, D. Effect of strain rate on ductile fracture initiation in advanced high strength steel sheets: Experiments and modeling. Int. J. Plast. 2014, 56, 19-44. [CrossRef]

65. Pehlke, R.D.; Jeyarajan, A.; Wada, H. Summary of Thermal Properties for Casting Alloys and Mold Materials; University of Michigan: Ann Arbor, MI, USA, 1982.

66. Wang, W.; Yang, M.X.; Yan, D.S.; Jiang, P.; Yuan, F.P.; Wu, X.L. Deformation mechanisms for superplastic behaviors in a dual-phase high specific strength steel with ultrafine grains. Mater. Sci. Eng. A 2017, 702, 133-141. [CrossRef]

(C) 2017 by the authors. Licensee MDPI, Basel, Switzerland. This article is an open access article distributed under the terms and conditions of the Creative Commons Attribution (CC BY) license (http:/ / creativecommons.org/licenses/by/4.0/). 